EDITORIAL

\title{
Are life events related to the onset of breast cancer? ${ }^{1}$
}

At present there is considerable interest in the relationship between psychosocial factors and illness, and particularly the role they might play in the onset and course of illness. In the field of oncology, one line of enquiry concerns the possible association between stressful life events and the onset of cancer. A recent editorial entitled 'Stressful life events and cancer' (Kune, 1994), for example, assumes that an association between the two has been convincingly demonstrated, and argues that the next step is the application of this information to prevention. Claims of a relationship between life events and the onset of cancer find a ready audience in the general community. Baghurst $e t$ al. (1992) reported that about $40 \%$ of a community-based sample believed that stress was a risk factor for breast cancer. Furthermore, those with cancer, or their families, may be prepared to believe that the disease is somehow due to too much stress, a partner or close friend dying, or prolonged depression and related emotional ill-health. The psychological fall-out from such beliefs may have important consequences for the way patients and their families view this potentially life threatening illness. In a similar vein, researchers may make far-reaching recommendations on the basis of findings (Cheang \& Cooper, 1985; Bremond et al. 1986), and in textbooks for training of health professionals, considerable weight is sometimes given to the supposed influence of life events on the subsequent development of cancer (e.g. Prokop et al. 1991). This being so, we believe that the validity of claims about life events and cancer needs to be critically examined.

\section{LIFE EVENTS AND ONSET OF BREAST CANCER}

We examine here the evidence for a relationship between life events and the development (incidence) of breast cancer. We emphasize the incidence of breast cancer, as the question of the influence of life events on clinical course and survival after diagnosis is really a different topic, with its own methodological problems. The focus on breast cancer is due, in part, to the relatively larger amount of research on breast cancer compared with cancer at other sites. Our interest in this topic also comes from two papers published in this journal purporting to show significant relationships between particular kinds of antecedent life events and the subsequent diagnosis of breast cancer (Cooper et al. 1989, Cooper \& Faragher, 1993). Our aim is to review briefly the available evidence and to highlight the difficulties we see in accepting that such relationships have been convincingly demonstrated. At the outset, we acknowledge the difficulty in testing hypotheses about the relationship between life events and cancer onset. For practical reasons, most research is retrospective in nature; in the present context, relying on recall of life events by women usually prior to knowledge of the outcome of their breast biopsy, but after they had noted breast symptoms and had been referred for a suspected breast problem. The difficulties involved in such recall are well known, particularly those relating to response bias (Kune et al. 1991). Consequently, conclusions based upon this method need to be considered in the light of its limitations.

\section{THE STUDIES}

Table 1 presents information on those studies published over the last two decades, examining the relationship between life events and onset of breast cancer. These studies were identified from literature searches, earlier reviews and individual published papers. There were 14 papers in all; the

\footnotetext{
1 Address for correspondence: Dr Rob McGee, Group for Behavioural Research in Cancer, Hugh Adam Cancer Epidemiology Unit, Department of Preventive and Social Medicine, Medical School, University of Otago, Dunedin, New Zealand.
} 
Table 1. Summary of studies examining life events and breast cancer

\begin{tabular}{|c|c|c|c|c|}
\hline Study authors & Sample size & Age distribution & Recall period & Association between cancer and life events \\
\hline $\begin{array}{l}\text { Snell \& Graham } \\
(1971)\end{array}$ & $\begin{array}{l}352 \text { cases } \\
670 \text { controls* }\end{array}$ & Cases $<$ Controls & $\begin{array}{l}5 \text { years prior to } \\
\text { diagnosis }\end{array}$ & $\begin{array}{l}\text { No differences in separations, divorces, family } \\
\text { illness or a range of other life events. }\end{array}$ \\
\hline $\begin{array}{l}\text { Schonfield } \\
(1975)\end{array}$ & $\begin{array}{l}27 \text { cases } \\
85 \text { controls** }\end{array}$ & Cases $>$ Controls & $\begin{array}{l}3 \text { years prior to } \\
\text { diagnosis }\end{array}$ & $\begin{array}{l}\text { Controls reported more life changes; no } \\
\text { differences in loss or separation events }\end{array}$ \\
\hline $\begin{array}{l}\text { Greer \& Morris } \\
\text { (1975) }\end{array}$ & $\begin{array}{l}69 \text { cases } \\
91 \text { controls** }\end{array}$ & Cases $>$ Controls & $\begin{array}{l}5 \text { years prior to } \\
\text { breast lump }\end{array}$ & $\begin{array}{l}\text { No differences in amount or type of stress; no } \\
\text { differences in loss events. }\end{array}$ \\
\hline $\begin{array}{l}\text { Scherg et al. } \\
\text { (1981) }\end{array}$ & $\begin{array}{l}100 \text { cases } \\
100 \text { controls*** } \\
\text { Subset: } \\
69 \text { cases } \\
69 \text { controls** }\end{array}$ & Cases $=$ Controls & Recent? & $\begin{array}{l}\text { Cases report more deaths of close relative in } \\
\text { past } 3 \text { years than controls*** }(46 \% \text { v. } 31 \%) \text {. }\end{array}$ \\
\hline $\begin{array}{l}\text { Cheang \& Cooper } \\
(1985) \dagger\end{array}$ & $\begin{array}{l}46 \text { cases } \\
75 \text { controls*** } \\
42 \text { controls*** }\end{array}$ & $\begin{array}{l}\text { Cases }=\text { Controls } \\
\text { Cases }>\text { Controls }\end{array}$ & $\begin{array}{l}2 \text { years prior to } \\
\text { biopsy }\end{array}$ & $\begin{array}{l}\text { Cases had higher life events scores than } \\
\text { controls; no differences among groups in loss } \\
\text { events; cases report more illness events than } \\
\text { controls*** }(78 \% \text { v. } 50 \%) \text {. }\end{array}$ \\
\hline $\begin{array}{l}\text { Priestman et al. } \\
\text { (1985)† }\end{array}$ & $\begin{array}{l}100 \text { cases } \\
100 \text { controls } \\
100 \text { controls*** }^{* *}\end{array}$ & Cases $>$ Controls & $\begin{array}{l}3 \text { years prior to } \\
\text { diagnosis }\end{array}$ & $\begin{array}{l}\text { No difference between cases and controls** in } \\
\text { life events; controls }{ }^{* * *} \text { reported more life } \\
\text { events than other two groups. }\end{array}$ \\
\hline $\begin{array}{l}\text { Bremond et al. } \\
\text { (1986) }\end{array}$ & $\begin{array}{l}50 \text { cases } \\
105 \text { controls*** }\end{array}$ & Cases $=$ Controls & $\begin{array}{l}5 \text { years prior to } \\
\text { surgery }\end{array}$ & $\begin{array}{l}\text { No overall difference between cases and } \\
\text { controls; on re-analysis, no difference in } \\
\text { younger or older groups. }\end{array}$ \\
\hline $\begin{array}{l}\text { Cooper et al. } \\
(1989) \dagger\end{array}$ & $\begin{array}{l}171 \text { cases } \\
155 \text { cysts } \\
1110 \text { controls** } \\
727 \text { controls*** }\end{array}$ & Cases $>$ Controls & $\begin{array}{l}2 \text { years prior to } \\
\text { referral by GP }\end{array}$ & $\begin{array}{l}\text { Cases reported lower summated incidence of } \\
\text { events and lower severity ratings for events; } \\
\text { on re-analysis, death of friend }(12 \% \text { v. } 5 \%) \\
\text { and retirement }(8 \% \text { v. } 2 \%) \text { more common } \\
\text { among cases than controls.*** }\end{array}$ \\
\hline $\begin{array}{l}\text { Edwards et al. } \\
(1990) \dagger\end{array}$ & $\begin{array}{l}79 \text { cases } \\
505 \text { controls** } \\
397 \text { controls*** }^{* *}\end{array}$ & Cases $=$ Controls & $\begin{array}{l}2 \text { years prior to } \\
\text { mammography }\end{array}$ & $\begin{array}{l}\text { No difference between cases and both controls } \\
\text { on life event scales of occurrence or severity; } \\
\text { cases report more surgery than both controls } \\
(44 \% y .19 \%) \text { and more threats to job than } \\
\text { controls*** }(7 \% \text { v. } 1 \%) \text {. }\end{array}$ \\
\hline $\begin{array}{c}\text { Forsen } \\
(1991)\end{array}$ & $\begin{array}{l}87 \text { cases } \\
87 \text { controls*** }\end{array}$ & Cases $=$ Controls & $\begin{array}{l}6 \text { years prior to } \\
\text { surgery }\end{array}$ & $\begin{array}{l}\text { No differences in experience of losses and } \\
\text { separations; cases report greater severity of } \\
\text { loss and more difficult life situations than } \\
\text { controls in prior } 2 \text { years }(54 \% \text { v. } 7 \% \text { ). }\end{array}$ \\
\hline $\begin{array}{l}\text { Geyer } \\
(1993) \dagger\end{array}$ & $\begin{array}{l}33 \text { cases } \\
20 \text { controls* } \\
59 \text { controls** }^{*}\end{array}$ & Cases $>$ Controls & $\begin{array}{l}8 \text { years prior to } \\
\text { surgery }\end{array}$ & $\begin{array}{l}\text { Cases report more severe 'contextual threats' } \\
(48 \%) \text { than controls" }(10 \%) \text { and controls** } \\
(15 \%) \text {, and more severe loss events }(45 \% v \text {. } \\
12 \%) \text { than controls.** }\end{array}$ \\
\hline \multicolumn{5}{|l|}{ Bereavement } \\
\hline $\begin{array}{l}\text { Muslin et al. } \\
\text { (1966) }\end{array}$ & $\begin{array}{l}37 \text { cases } \\
37 \text { controls }\end{array}$ & Cases $=$ Controls & $\begin{array}{l}3 \text { years prior to } \\
\text { diagnosis }\end{array}$ & $\begin{array}{l}\text { No differences in permanent loss of relatives or } \\
\text { significant friends. }\end{array}$ \\
\hline $\begin{array}{l}\text { Jones et al. } \\
(1984)\end{array}$ & $\begin{array}{l}1 \% \text { sample } \\
\text { of census }\end{array}$ & Cohort study & & No differences in widowhood. \\
\hline $\begin{array}{c}\text { Ewertz } \\
(1986)\end{array}$ & $\begin{array}{l}1792 \text { cases } \\
1739 \text { controls }\end{array}$ & $\begin{array}{l}\text { Age stratified } \\
\text { sampling }\end{array}$ & $\begin{array}{l}<3 \text { to }>15 \text { years } \\
\text { prior to diagnosis }\end{array}$ & No differences in widowhood. \\
\hline
\end{tabular}

Controls: * hospitalized women with other illness; ${ }^{* *}$ women with benign tumours of the breast; *** well-women. †Cases compared individually with each control group using post-hoc criteria proposed by Everitt (1977).

final three listed in Table 1 specifically examined the relationship between bereavement and cancer. Of these, one was a cohort study based upon cancer registration and mortality data, and census data (Jones et al. 1984). The same data presented by Cooper et al. (1989) have been re-analysed by Cooper \& Faragher (1993); we have cited only the former paper in the table. We have listed the authors, the sample sizes and nature of controls, the recall period for life events, and the findings of each study. Before examining the findings, however, it is worth pointing out four important features of the studies that might influence any conclusions to be drawn. 


\section{Age differences between cases and controls}

Inspection of Table 1 indicates the presence of significant age differences between the women in the case and control groups in seven of the published studies. In all but one of these, cases were significantly older than controls with mean differences of 3 years (Priestman et al. 1985), 6 years (Cheang \& Cooper, 1985; Geyer, 1993) and 16 years (Cooper et al. 1989). In the two studies where age distributions were given, cases were nearly two (Schonfield, 1975) and three times (Greer \& Morris, 1975) more likely than controls to come from the older age ranges. Typically, studies have attempted to control for these differences by statistical means, altliough no evidence was presented to indicate just how successful such attempts were. However, this is not a trivial issue. As a woman's age increases so does her risk of breast cancer (Kelsey \& Horn-Ross, 1993). At the same time, while older women may well experience fewer overall life events than younger women, it is likely they will experience particular kinds of life events such as death of a partner or other family members or friends, retirement and so on (George, 1990). So, age may act as a source of confounding in examining possible effects on cancer incidence of specific kinds of life events such as these.

To take an example, after controlling for age using a multiple logistic regression model comparing cases with well women, Cooper et al. (1993) conclude that severity of stress relating to marriage, pregnancy and birth of a baby occurring in the 2 years prior to referral increased the risk of subsequent cancer, while an apparently minor event such as moving or buying a house was somehow protective. From the life event occurrence data, we estimate that at the most, about 12 of the 171 cases experienced these particular marriage/birth events. Given the mean age of the cases of 55 years and of controls of 39 years, it would not be surprising that these women found these kinds of life events more stressful. Furthermore, to assess an association between stress and such events requires that any biological effect of the event itself must also be assessed. There is evidence to suggest the existence of a transient increase in the risk of breast cancer following a full-term pregnancy, over and above any increase associated with ageing alone (Bruzzi et al. 1988; Lambe et al. 1994). Moreover, the risk of breast cancer varies not only by age but by marital status, parity, and age at first pregnancy (Harris et al. 1993; Kelsey et al. 1993). It may be that part of the effect attributed to life event stress is due to the reproductive histories of some of the women.

The results of Cooper \& Faragher (1993) are presented as regression coefficients so it is difficult to assess the size of the effects associated with meaningful change in each variable. One way of examining these findings is to use odds ratios (ORs) based upon the age adjusted regression coefficients provided in the comparison of cases with well women controls (see Cooper \& Faragher, Table 4b, p. 659). These suggest that the OR for cancer for a 1 year increase in age is $1.09(95 \%$ $\mathrm{CI}: 1.07$ to 1.11 ), and translated into a 10 year interval (which is about one standard deviation unit) the OR is 2.43 (95\% CI: 2.04 to 2.90$)$; this attests to the highly significant and large effect of age on cancer incidence among this group of women. By contrast, the OR for an increase in one standard deviation unit in marriage-pregnancy-birth incidence severity ratings is $1.10(95 \% \mathrm{CI}$ : 1.02 to 1.19$)$ and 0.96 for the effect of property related severity ratings (95\% CI: 0.92 to 0.98$)$. We would argue that while the sizes of effects associated with event severity are statistically significant they are quite small, and could well be due to uncontrolled age effects in the data. Given the 16 year average age difference between the cases and controls in this study, how likely is it that the regression analyses adequately control for the effects of age?

The underlying assumption of such models is that the effect of age on breast cancer is linear. However, the variation in risk of breast cancer with age, from age 20 to 65 years, is in fact not linear (Kelsey \& Horn-Ross, 1993). Furthermore, where the frequencies of life events are adjusted for age the assumption is that the slope between age and the logit (life event) is similar for each group (Hosmer \& Lemeshow, 1989). It seems possible that this is not the case, and in practice this assumption may be difficult to test in regression models because of the low incidence of many of the life events. 


\section{Measurement of life events}

There has been considerable debate concerning the appropriateness of different methods of assessing life events (e.g. Brown, 1974; Paykel \& Rao, 1984). An important issue is the extent to which self-report 'checklists' of life events provide valid and reliable measures of life stresses. This approach may be contrasted with one based upon detailed interviews which aim to elaborate the biographical context surrounding a particular life event and the degree of threat to the individual, as rated by the investigator rather than the respondent. More recent recommendations have included some consideration of the extent to which life events might represent opportunities as well as hazards, so that event resolution becomes an important consideration (Turner \& Avison, 1992). It is not our intention to review this debate here. Rather, we would note that in the 14 studies identified in Table 1, the predominant measurement technique has involved the checklist approach where a list of events is rated for frequency of occurrence and sometimes the self-perceived severity of stress associated with a particular event. Only one study (Geyer, 1993) used a finely detailed interview to assess life events. At the other extreme, Bremond et al. (1986) simply asked whether the respondent had a serious 'psychological shock during the past 5 years', and included a brief list of examples such as loss of husband, close relative or friend, or serious illness. In general, then, the procedures used in this research have involved the weaker methods for the measurement of life event stress.

\section{Recall period}

The women were asked to recall life events occurring in the years preceding diagnosis or surgery, and seven studies used relatively short recall periods of 2 or 3 years. However, the causative factors for breast cancer act many years, perhaps 20 or more, before the onset of symptoms or the diagnosis of disease (Harris et al. 1993). Studies of breast cancer screening show that the likely time taken for a cancer to grow from the minimum screen detectable size to a size likely to give clinical symptoms is between 1 and 4 years (Walter \& Day, 1983). Thus, an association with a factor acting in the 2 to 5 years before diagnosis will more probably relate to the diagnosis of an existing cancer, or to later stage tumour promotion, rather than to primary causation. A standard technique in aetiological studies is to compare the associations given by using different time intervals, with a true causal factor giving a stronger association with a long interval prior to diagnosis. None of the studies has used such methods, or distinguished between primary causes, later stage promotion, or influences on help seeking and subsequent diagnosis of the disease.

\section{Multiple significance tests}

Several studies reported multiple tests of significance for both occurrence and severity at the level of summated event ratings, summated ratings for subtypes of life events, and ratings of individual life events; in one instance this involved well over 100 statistical tests (Edwards et al. 1990). While ostensibly testing for differences among case and control groups at the $P<0.05$ level of significance, multiple significance testing such as this with an unprotected Type I error rate can lead to a true error rate well above the nominal 0.05 level (Hays, 1969), and there is clearly a strong possibility of making correlated decision errors. Furthermore, some studies report such unprotected analyses on post-hoc recombinations or subdivisions of cases and control groups (e.g. grouping women with breast cysts and well-women, or subdividing groups by age). Given that these analyses follow inspection of the data, this procedure requires careful justification as there is the potential for capitalising on chance variations in the data.

In those studies with more than one control group, we have re-analysed the data where possible using an overall chi-square test among groups followed by post-hoc comparisons of cases with each control group using a protected test as proposed by Everitt (1977). We believe this to be an appropriate analysis strategy given the extent of multiple significance testing and unprotected posthoc comparisons among groups in some of the studies. For this reason, study outcome in terms of significance of findings as presented in Table 1, may differ from interpretations of results given in the original paper. 


\section{IS THERE A RELATIONSHIP BETWEEN LIFE EVENTS AND ONSET OF BREAST CANCER?}

Hypotheses concerning the relationship between life stress and onset of breast cancer are to a certain extent limited by the way life events typically have been measured in these studies. However, it would seem reasonable to hypothesize that risk of a subsequent diagnosis of breast cancer might be associated with any or all of the following: (a) the cumulative number of life events experienced; $(b)$ the cumulative amount of self-perceived stress experienced; and $(c)$ the experience of particularly salient types of life stress. What, then, do the findings suggest? In terms of the "summated experience', there seems to be no consistency in the findings. In three studies (Schonfield, 1975; Priestman et al. 1985; Cooper et al. 1989), the cases reported fewer total life events than the controls. Five others found no differences in total life events (Scherg et al. 1981; Snell \& Graham, 1971; Greer \& Morris, 1975; Bremond et al. 1986; Edwards et al. 1990). Cheang \& Cooper (1985) found that cases reported an average of one life event more than non-cancer or well controls, but cases and non-cancer controls did not differ in terms of severity of stress experienced. Geyer (1993) reported that cases were more likely than controls to rate experienced events as more threatening, but it is unclear from the results whether cases experienced more life events overall. Perhaps the strongest positive difference is in the study of Forsen (1991) where 'difficult life situations' were nearly eight times more common among the cases than among community selected controls. It should be noted, however, that the cases were women with operable breast cancer who were interviewed while still in the hospital ward after surgery and apparently knew they had cancer. Similarly, in the Bremond et al. (1986) study, cases knew the diagnosis at the time of interview.

Salient types of life event stress might include significant loss related to the immediate family or very close friends. With respect to bereavement or loss of family members or close friends, the evidence is not particularly strong. Four studies suggested an association between such loss and the development of breast cancer. Scherg et al. (1981) reported more deaths of close relatives among cases than well women. Cooper et al. (1989) found more deaths of a close friend among cases, although cases did not differ from controls in terms of death of husband or other family member, or separation from a loved one. Forsen (1991) reported no differences in the occurrence of loss and separation between cases and controls although cases rated such losses as more severe. Similarly, Geyer (1993) reported cases were more likely to rate events experienced as higher on a dimension of loss. All other studies found no association between significant loss and cancer.

At the level of other specific life events, there was evidence that cases reported more illness and medical interventions than controls (Cheang \& Cooper, 1985; Edwards et al. 1990) and it is of note in the latter study that $44 \%$ of cases reported 'a previous history of cancer'. Most of these women were attending a clinic for a routine examination and mammography, and consequently were probably quite similar to samples in other studies. Similarly, Scherg (1987) reported that over half the women with breast cancer in his sample had a breast lesion found in a previous examination. Previous history of breast lesions does not appear to have been assessed in other studies although this would seem to be a critical variable in examining life event history. Higher rates of previous history of illness, medical interventions, and history of cancer among cases may also account for findings that cases more frequently admit a fear of breast cancer than controls (Scherg, 1987) and are more likely to believe (correctly) that they have breast cancer prior to diagnosis (Engelman \& Craddick, 1984). This seems to be an unexamined source of bias in most studies using retrospective recall. In terms of other life events, the data of Cooper et al. (1989) suggested greater experience of retirement in cases compared with controls, and Edwards et al. (1990) reported more threats of job loss among cases compared with well-women. In both instances these differences involved relatively few cases.

\section{CONCLUSION}

It is possible to develop very elaborate models of the way life events might impact upon the person's mind and body, thereby increasing an individual's risk of cancer, and several authors have indeed 
done so. We would agree with the assessment of Stein et al. (1991), however, that the real need in this research area is not for more elaborate models but for clear demonstrations that psychosocial variables and diseases such as cancer are related at all. Such demonstrations should rely on subjecting falsifiable hypotheses about the relationship between psychosocial variables and subsequent diagnosis of cancer to as strong a test as the methodology allows. At the same time, the development and testing of hypotheses concerning psychosocial factors and cancer needs to be constrained by a certain degree of biological plausibility. In the context of research on life events, it seems reasonable to hypothesize that cumulative life stress or particularly salient sources of stress might be more strongly predictive of cancer. It is our contention that neither of these hypotheses receives much support from the evidence outlined in Table 1 . What we seem to be left with is a handful of associations between highly specific life events such as marriage-pregnancy related events, threats to employment, or moving house, and breast cancer. It may be possible to identify plausible post-hoc reasons why specific events such as these are related to a diagnosis of breast cancer. However, given the inconsistency of findings related to these kinds of specific events their evidentiary value is weak at best.

What is needed is some refinement in the types of hypotheses entertained about how life events might be expected to influence subsequent cancer incidence. This would imply some hierarchy of evidence which can then be evaluated. This seems particularly important given the methodological difficulties this type of research faces. As it is, discussion of findings is to a large extent ad hoc where any effects, however weak, are given equal value. Overall, the evidence does not confirm the hypothesis that there is an association between life events and onset of breast cancer. Indeed, we would argue that the research has not provided a strong enough test of the hypothesis to draw any firm conclusions regarding the relationship between life events and breast cancer.

\section{R. MCGEE, S. WILLIAMS AND M. ELWOOD}

The authors wish to acknowledge the support of the Cancer Society of New Zealand in the preparation of this paper.

\section{REFERENCES}

Baghurst, K. I., Baghurst, P. A. \& Record, S. J. (1992). Public perceptions of the role of dietary and other environmental factors in cancer causation or prevention. Journal of Epidemiology and Community Healh 46, 120-126.

Bremond, A., Kune, G. A. \& Bahnson, C. B. (1986). Psychosomatic factors in breast cancer patients. Results of a case control study. Journal of Psychosomatic Obstetrics and Gynaecology 5, 127-136.

Brown, G. W. (1974). Meaning, measurement, and stress of life events. In Stressful Life Events: Their Nature and Effects (ed. B. S. Dohrenwend and B.P. Dohrenwend), pp. 217-243 Wiley: New York.

Bruzzi, P., Negri, E., La Vecchia, C., Decarli, A., Palli, D., Parazzini, F. \& Del Turco, M. R. (1988). Short term increase in risk of breast cancer after full term pregnancy. British Medical Journal 297, 1096-1098.

Cheang, A. \& Cooper, C. L. (1985). Psychosocial factors in breast cancer. Stress Medicine, 1, 61-66.

Cooper,C. L. \& Faragher, E. B. (1993). Psychosocial stress and breast cancer: the inter-relationship between stress events, coping strategies and personality. Psychological Medicine 23, 653-662.

Cooper, C. L., Cooper, R. \& Faragher, E. B. (1989). Incidence and perception of psychosocial stress: the relationship with breast cancer. Psychological Medicine 19, 415-422.

Edwards, J. R., Cooper, C. L., Pearl, S. G., de Parades, E. S., O'Leary, T. \& Wilhelm, M. C. (1990). The relationship between psychosocial factors and breast cancer: some unexpected results. Behavioral Medicine 16, 5-14.
Engelmán, S. R. \& Craddick, R. (1984). The symbolic relationship of breast cancer patients to their cancer, cure, physician, and themselves. Psychotherapy and Psychosomatics 41, 68-76.

Everitt, B. S. (1977). The Analysis of Contingency Tables. Chapman \& Hall: London.

Ewertz, M. (1986). Bereavement and breast cancer. British Journal of Cancer 53, 701-703.

Forsen, A. (1991). Psychosocial stress as a risk for breast cancer. Psychotherapy and Psychosomatics 55, 176-185.

George, L. K. (1990). Stress, social support, and depression over the life-course. In Aging, Stress and Heahh (ed. K. S. Markides and C. L. Cooper), pp. 241-267. John Wiley \& Sons: Chichester.

Geyer, S. (1993). Life events, chronic difficulties and vulnerability factors preceding breast cancer. Social Science and Medicine 37, 1545-1555.

Greer, S. \& Morris, T. (1975). Psychological attributes of women who develop breast cancer: a controlled study. Journal of Psychosomatic Research 19, 147-153.

Harris, J. R., Morrow, M. \& Bonadonna, G. (1993). Cancer of the breast. In Cancer Principles and Practice of Oncology (ed. V.T. DeVita Jr., S. Hellman and S. A. Rosenberg), pp. 1264-1332. Lippincott Co: Philadelphia.

Hays, W. (1969). Statistics. Holt, Rinehart \& Winston: London.

Hosmer, D. W. \& Lemeshow, S. (1989). Applied Logistic Regression Wiley \& Sons: New York.

Jones, D. R., Goldblatt, P. O. \& Leon, D. A. (1984). Bereavement and cancer: some data on deaths of spouses from the longitudinal study of Office of Population Censuses and Surveys. British Medical Journal 289, 461-464. 
Kelsey, J. L. \& Horn-Ross, P. L. (1993). Breast cancer: magnitude of the problem and descriptive epidemiology. Epidemiologic Reviews 15. 7-16.

Kelsey, J. L., Gammon, M. D. \& John, E. M. (1993). Reproductive fictors and breast cancer. Epidemiologic Review's 15, 36-47.

Kunc, G. A., Kune. S., Watson, L. F. \& Bahnson, C. B. (1991). Personality as a risk factor in large bowel cancer: data from the Melbourne Colorectal Cancer Study. Psychological Medicine 21, 29-41.

Kunc, S. (1993). Stressful life events and cancer. Epidemiology 4. 395-397.

Lambc. M.. Hsieh, C.. Trichopoulos, D., Ekbom, A., Pavia, M. \& Adami, H. O. (1994). Transient increase in the risk of breast cancer after giving birth. New England Journal of Medicine 331, 5-9.

Muslin. H. L., Gyarfas, K. \& Pieper, W. J. (1966). Separation experience and cancer of the breast. Ammals of the New York Academy of Sciences 125, 802-806.

Paykel, E. S. \& Rao, B. M. (1984). Methodology in studies of life events and cancer. In Psychosocial Stress and Cancer (ed. C. L. Cooper). pp. 73-89. John Wiley \& Sons: Chichester.

Priestman, T. J., Priestman, S. G. \& Bradshaw, C. (1985). Stress and breast cancer. British Journal of Cancer 51, 493-498.
Prokop, C. K., Bradley, L. A., Burish, T. G., Anderson, K. O. \& Fox, J.E. (1991). Health Psychology: Clinical Methods and Research. MacMillan: New York.

Scherg, $H$. (1987). Psychosocial factors and disease bias in breast cancer patients. Psychosomatic Medicine 49, 302-312.

Scherg, H., Cramer, I. \& Blohmke, M. (1981). Psychosocial factors and breast cancer: a critical reevaluation of established hypotheses. Cancer Detection and Prevention 4, 165-171.

Schonfield, J. (1975). Psychological and life-experience differences between Israeli women with benign and cancerous breast lesions. Journal of Psychosomatic Research 19, 229-234.

Snell, L. \& Graham, S. (1971). Social trauma as related to cancer of the breast. British Journal of Cancer 25, 721-734.

Stein, M., Miller, A. H. \& Trestman, R. L. (1991). Depression, the immune system, and health and illness. Archives of General Psychiarry 48, 171-177.

Turner, R. J. \& Avison, W. R. (1992). Innovations in the measurement of life stress: crisis theory and the significance of event resolution. Journal of Health and Social Behavior 33, 36-50.

Walter, S. D. \& Day, N. E. (1983). Estimation of the duration of preclinical disease state using screening data. American Journal of Epidemiology 118, 865-886. 